\title{
RANCANG BANGUN SISTEM PENSTABIL KAMERA (GIMBAL) DENGAN LOGIKA FUZZY UNTUK PENGAMBILAN GAMBAR FOTO DAN VIDEO
}

\author{
Fahmizal $^{1}$, Georgius Yoga Dewantama ${ }^{2}$, Donny Budi Pratama ${ }^{3}$, Fahmi Fathuddin ${ }^{4}$, Winarsih ${ }^{5}$ \\ 1,2,3,4,5 Departemen Teknik Elektro dan Informatika, Sekolah Vokasi, Universitas Gadjah Mada \\ Email: ${ }^{1}$ fahmizal@ugm.ac.id, ${ }^{2}$ georgius.yoga.d@mail.ugm.ac.id, ${ }^{3}$ donny.budi.p@mail.ugm.ac.id \\ ${ }^{4}$ fahmy.fathuddin@ugm.ac.id, ${ }^{5}$ winarsih0210@ugm.ac.id
}

(Naskah masuk: 22 April 2018, diterima untuk diterbitkan: 4 Juni 2018)

\begin{abstract}
Abstrak
Pada makalah ini memaparkan perancangan sistem penstabil kamera (gimbal) untuk mengurangi getaran maupun gerakan yang akan mengganggu kamera saat pengambilan gambar foto dan video. Sistem gimbal ini sangat penting digunakan dalam dunia fotografi dan videografi. Sistem gimbal yang dirancang pada penelitian ini adalah dengan tiga buah joint pergerakan yaitu roll, pitch, yaw (RPY). Sensor orientasi yang digunakan pada rancangan sistem gimbal ini menggunakan sensor inertia measurement unit (IMU) MPU 6050 dengan Kalman filter (KF) sebagai pengkondisi pembacaan sudut RPY. Untuk memperoleh hasil gambar yang baik pada sistem gimbal diperlukan suatu kendali, sehingga pada penelitian ini dikembangkan suatu kendali logika fuzzy yang diimplementasikan dalam sebuah mikrokontroller untuk menggerakan aktuator gimbal. Sistem aktuator pada rancangan gimbal menggunakan motorservo. Nilai setpoint sudut gimbal yang diberikan merupakan sudut elevasi gimbal terhadap tiga sumbu sudut RPY. Selanjutnya, nilai keluaran pembacaan sensor IMU dibandingkan dengan nilai setpoint pada masing-masing sumbu. Setelah itu, nilai kesalahan (error) dan nilai perubahan kesalahan (delta errror) yang didapat akan digunakan sebagai nilai masukan logika fuzzy. Terdapat tiga buah loop tertutup pada kendali logika fuzzy untuk masing-masing sudut RPY. Hubungan relasi masukan fuzzy diselesaikan menggunakan aturan Mamdani dan keluaran dari logika fuzzy diselesaikan dengan menggunakan metode weight average (WA). Dari hasil pengujian diketahui bahwa kendali logika fuzzy yang diimplementasikan pada sistem gimbal mampu mengurangi efek getaran sehingga diperoleh gambar yang baik dan tidak blur.
\end{abstract}

Kata kunci: Gimbal kamera, Logika Fuzzy, Sensor IMU, Kalman filter.

\section{Design a Camera Stabilizer System (Gimbal) with Fuzzy Logic for Photo and Video Taking}

\begin{abstract}
This paper describes the design of the camera stabilizer system (gimbal) to reduce vibration or movement that will disturb the camera when take a picture and video. This gimbal system is very important used in the world of photography and videography. Gimbal system that designed in this research is gimbal with three joints movement that is roll, pitch, yaw (RPY). The orientation sensor that used in this gimbal system design uses an inertial measurement unit sensor (IMU) MPU 6050 with Kalman filter (KF) as RPY angle reading conditioner. To obtain a good image on the gimbal system required a control, so in this research developed a fuzzy logic control that is implemented in a microcontroller to drive gimbal's actuators. The actuators system on gimbal design uses motorservo. The given setpoint value of the gimbal is the elevation angle of gimbal against the three RPY angle axes. Furthermore, the output value of the IMU sensor is compared with the setpoint of each axis. Moreover, the error value and the change of error value (delta errror) will be used as fuzzy logic input. There are three closed loops on the fuzzy logic control for each RPY angle. The relation of fuzzy input is solved with Mamdani rule and the output of fuzzy logic is solved with weight average (WA). From the test results obtained that fuzzy logic control applied to the gimbal system is able to reduce the effects of vibration so as to obtain a good image and not blur.
\end{abstract}

Keywords: Gimbal Camera, Fuzzy Logic, IMU Sensor, Kalman Filter. 


\section{PENDAHULUAN}

Penstabil kamera atau familier dengan nama gimbal adalah alat penstabil kamera yang berfungsi untuk menghasilkan gambar atau video tanpa terpengaruh oleh kemiringan atau guncangan yang terjadi ketika pengambilan gambar atau video berlangsung. Pengunaan gimbal sering digunakan ketika pengambilan gambar dengan pesawat tanpa awak unamed aerial vehicle (UAV) (Ubaya and Mawarni, 2014). Selain itu di dunia per-film-an, gimbal menjadi key point untuk memperoleh suatu gambar dan video yang baik. Hasil gambar dan video dapat dipengaruhi oleh berbagai ganguan-gangguan sehingga menghasilkan gambar dan video yang kurang fokus dan terjadi efek blur atau bisa juga menyebabkan hasil video menjadi berguncang dan tidak stabil (Knoblauch, Tuma and Schnettler, 2015). Maka dari itu, pada makalah ini dilakukan penelitian untuk merancang dan mengimplementasikan suatu sistem gimbal yang dapat menstabilkan posisi kamera saat dibawa bergerak dan menerima berbagai macam gangguan.

Penelitian yang dilakukan oleh (Priyambodo, 2017) memanfaatkan gimbal dengan dua sumbu gerak untuk rancangan sistem penstabil kamera. Pada penelitian tersebut, sistem kendali yang diterapkan menggunakan PID kontroler dengan tuning ZieglerNichols. Penelitian ini menggunakan motor brushless sebagai aktuatornya dengan alasan memiliki respon yang lebih baik. Hasil yang diperoleh pada penelitian ini baru menyelesaikan persoalan gerak pada dua sumbu saja. Oleh karena itu perlu dilanjut pada pergerakan yang lebih dari dua sumbu. Selanjutnya penelitian yang dilakukan oleh (Haris, 2017) juga menerapkan sistem gimbal dengan dua sumbu gerak, namun pada penelitian ini sistem kendali yang diterapkan menggunakan PID fuzzy.

Dari tinjauan literatur penelitian tentang sistem gimbal lebih banyak membahas pada pergerakan dua sumbu. Maka dari itu, pada makalah ini akan menyajikan sebuah paparan perancangan sistem gimbal dengan memiliki pergerakan tiga buah sumbu. Sistem gimbal yang dirancang pada penelitian ini adalah dengan tiga buah sumbu pergerakan yaitu roll, pitch, yaw (RPY). Sensor orientasi yang digunakan pada rancangan sistem gimbal ini menggunakan sensor inertia measurement unit (IMU) MPU 6050 dengan Kalman filter (KF) sebagai pengkondisi pembacaan sudut RPY.

Untuk memperoleh hasil gambar yang baik pada sistem gimbal diperlukan suatu kendali, sehingga pada penelitian ini dikembangkan suatu kendali logika fuzzy. Sistem aktuator pada rancangan gimbal menggunakan motorservo. Nilai setpoint sudut gimbal yang digunakan adalah sudut elevasi gimbal terhadap tiga sudut RPY. Selanjutnya, nilai keluaran pada sensor IMU dibandingkan dengan nilai setpoint yang telah ditetapkan pada masing-masing sumbu.
Selanjutnya, nilai kesalahan (error) dan nilai perubahan kesalahan (delta errror) yang dihasilkan akan digunakan sebagai nilai masukan logika fuzzy. Hubungan relasi masukan fuzzy diselesaikan menggunakan aturan Mamdani dan keluaran dari logika fuzzy diselesaikan dengan menggunakan metode weight average (WA).

\section{METODE PENELITIAN}

\subsection{KINEMATIKA SISTEM GIMBAL}

Pada sub bab ini dijelaskan penurunan kinematika dari sistem gimbal yang disajikan pada Gambar 1. Kinematika sistem gimbal diamati secara maju (forward kinematics) dan dengan cara perhitungan geometri serta diasumsikann bahwa sistem gimbal dapat dilihat sebagai sistem multi body yang kaku (Croce et al., 2014). Untuk mendeskripsikan pergerakan rotasi sumbu $x, y, z$ atau sumbu sudut roll, pitch, yaw disajikan pada persamaan (1) dan pergerakan tranlasi sistem gimbal disajikan pada persamaan (2).

$$
\begin{aligned}
R_{x}\left(\theta_{3}\right)=R_{3}^{2}\left(\theta_{3}\right) & =\left[\begin{array}{ccc}
1 & 0 & 0 \\
0 & \cos \theta_{3} & -\sin \theta_{3} \\
0 & \sin \theta_{3} & \cos \theta_{3}
\end{array}\right] \\
R_{y}\left(\theta_{2}\right)=R_{2}^{1}\left(\theta_{2}\right) & =\left[\begin{array}{ccc}
\cos \theta_{2} & 0 & \sin \theta_{2} \\
0 & 1 & 0 \\
-\sin \theta_{2} & 0 & \cos \theta_{2}
\end{array}\right] \\
R_{z}\left(\theta_{1}\right)=R_{1}^{0}\left(\theta_{1}\right) & =\left[\begin{array}{ccc}
\cos \theta_{1} & -\sin \theta_{1} & 0 \\
\sin \theta_{1} & \cos \theta_{1} & 0 \\
0 & 0 & 1
\end{array}\right] \\
d_{1}^{0}(\theta) & =\left[\begin{array}{c}
L \sin \theta_{1} \\
L \cos \theta_{1} \\
H
\end{array}\right] \\
d_{2}^{1}(\theta) & =\left[\begin{array}{c}
B \cos \theta_{2} \\
L \\
B \sin \theta_{2}
\end{array}\right] \\
d_{3}^{2}(\theta) & =\left[\begin{array}{c}
-B \\
H \sin \theta_{3} \\
H \cos \theta_{3}
\end{array}\right]
\end{aligned}
$$

Untuk mengendalikan pergerakan dari sistem gimbal dengan kinematika maju dapat dilakukan dengan menggunakan metode Denavit Hartenberg atau lebih dengan nama metode DH (Shah, Saha and Dutt, 2012). Dengan menggabungkan matriks rotasi dan vektor translasi menghasilkan matriks transformasi homogen dari frame nol menuju end effector (frame ke tiga) seperti yang ditampilkan pada Gambar 1. Dengan menggabungkan vektor pergerakan rotasi dan translasi kedalam bentuk matriks transformasi homogen seperti yang disajikan pada persamaan (3).

$$
T_{1}^{0}=\left[\begin{array}{cc}
R_{1}^{0} & d_{1}^{0} \\
0 & 1
\end{array}\right]
$$


Dengan mengetahui hubungan semua hubungan matriks transformasi homogen dari frame ke nol menuju frame ke tiga maka bentuk matriks transformasi homogen sistem gimbal secara keseluruhan disajikan pada persamaan (4-6).

$$
T_{1}^{0}=T_{1}^{0} T_{2}^{1} T_{3}^{2}\left[\begin{array}{cc}
R_{3}^{0} & d_{3}^{0} \\
0 & 1
\end{array}\right]
$$

Dimana $R_{3}^{0}$ adalah

$$
R_{3}^{0}=\left[\begin{array}{ccc}
c_{1} c_{2} & c_{1} s_{2} s_{3}-c_{3} s_{1} & s_{1} s_{3}+c_{1} c_{3} s_{2} \\
c_{2} s_{1} & c_{1} c_{3}+s_{1} s_{2} s_{3} & c_{3} s_{1} s_{2}-c_{1} s_{3} \\
-s_{2} & c_{2} s_{3} & c_{2} c_{3}
\end{array}\right]
$$

Dan $d_{3}^{0}$ adalah

$$
d_{3}^{0}=\left[\begin{array}{c}
c_{1} c_{3} H_{3} s_{2}-H_{3} s_{1} s_{3} \\
2 c_{1} L_{1}+c_{1} H_{3} s_{3}+c_{3} H_{3} s_{1} s_{2} \\
H_{1}+2 B_{1} s_{2}+c_{2} c_{3} H_{3}
\end{array}\right]
$$

Penulisan subcript dari $c$ dan $s$ merupakan indikasi dari $\cos$ dan $\sin$ dari sudut pada $\theta_{1}, \theta_{2}, \theta_{3}$.
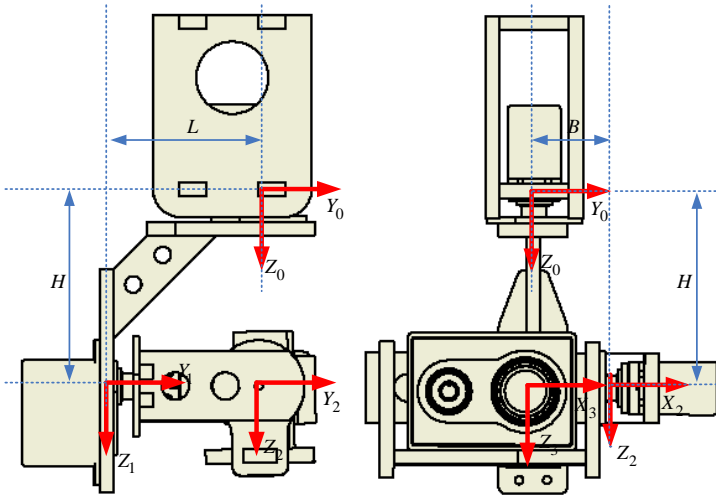

Gambar 1. Geometri sistem gimbal

\subsection{SENSOR IMU DAN KALMAN FILTER}

Inertial measurement unit (IMU) merupakan komponen elektronika yang memiliki kemampuan mengukur dan menampilkan kecepatan, orientasi, dan gaya gravitasi menggunakan kombinasi dari accelerometer dan gyroscope (Fahmizal, 2017). GY521 merupakan modul sensor berinti motion processing unit (MPU) seri 6050 yang terdiri dari enam axis dengan penambahan regulator tegangan dan beberapa komponen pelengkap lainnya yang membuat modul ini siap dipakai dengan tegangan supply sebesar 3-5VDC. Modul ini memiliki antarmuka I2C yang dapat disambungkan langsung ke mikrokontroler yang memiliki fasilitas I2C. Sensor MPU-6050 berisi sebuah MEMS Accelerometer dan sebuah MEMS Gyro yang saling terintegrasi. Sensor ini mampu membaca sudut secara akurat dengan fasilitas hardware internal 16 bit analog digital converter (ADC) untuk setiap kanalnya. Sensor ini akan membaca nilai kanal axis $x, y$ dan $z$ bersamaan dalam satu waktu. Gambar 2 merupakan tampilan fisik dari sensor IMU MPU 6050 .

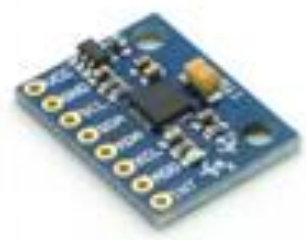

Gambar 2. Sensor IMU MPU 6050

Tabel 1. Spesifikasi dari modul IMU MPU 6050

\begin{tabular}{cc}
\hline Spesifikasi & Operasi \\
\hline Chip & MPU-6050 \\
Vin & $3 \mathrm{~V} \sim 5 \mathrm{~V}$ \\
Communication & $\mathrm{I} 2 \mathrm{C}$ \\
Gyroscopes ranges & $+/-25050010002000$ \\
degree/sec \\
Acceleration ranges & $+/-2 \mathrm{~g},+/-4 \mathrm{~g},+/-8 \mathrm{~g},+/-$ \\
Pin Spacing & $16 \mathrm{~g}$ \\
Built-in 16bit AD & $2.54 \mathrm{~mm}(0.1 \mathrm{in})$ \\
converter & 16 bit data output \\
\hline
\end{tabular}

Dalam penggunaan sensor IMU, noise adalah suatu gangguan yang perlu diperhatikan. Oleh karena itu, untuk mendapatkan sinyal sebenarnya yang terpisah dari sekumpulan noise, teknik penyaringan (filtering) sangat dibutuhkan. Pada penelitian ini, Kalman filter (KF) digunakan untuk menghilangkan noise. KF merupakan sebuah recursive filter yang memiliki estimasi state pada linear dynamics system dari rentetan pengukuran noise. Teknik filter ini dinamakan berdasarkan penemunya, Rudolf E. Kalman (Kalman, 1963).

Terdapat dua kelompok pada persamaan KF, persamaan time update dan persamaan measurement update. Time update dapat dikenal dengan proses predict, yaitu menggunakan estimasi state dari satu waktu sebelumnya untuk mendapatkan sebuah estimasi state pada saat ini. Sedangkan measurement update disebut juga sebagai proses correct, yaitu informasi pengukuran pada saat ini digunakan untuk memperbaiki prediksi dengan harapan akan didapatkan state estimasi yang lebih akurat. Sehingga dalam aplikasinya algoritma KF akan menggunakan proses perulangan dari predict dan correct seperti yang disajikan pada Gambar 3.

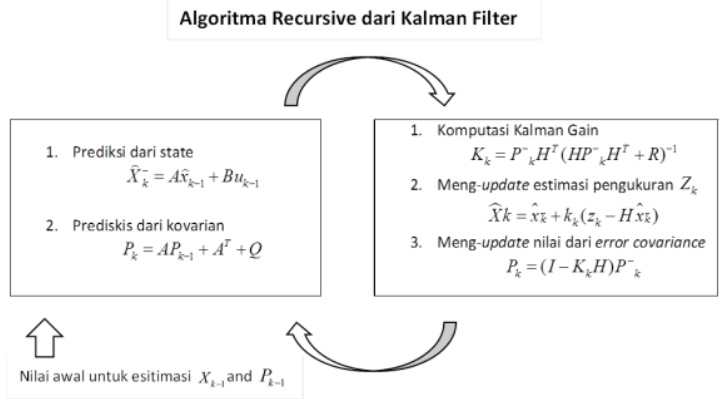

Gambar 3. Algoritma Kalman filter 


\subsection{SISTEM KENDALI FUZZY}

Logika fuzzy merupakan bagian prinsip matematika untuk menggambarkan pengetahuan berdasarkan derajat keanggotaan (degree of membership), berbeda dengan anggota krisp (crisp membership) pada logika biner klasik (Omar, 2010). Lain halnya dengan logika biner, logika fuzzy memiliki banyak nilai dan dipengaruhi dengan derajat keanggotaan dan derajat kebenaran (degree of truth). Logika biner menggunakan nilai krisp 0 (salah) atau 1 (benar), sementara logika fuzzy menggunakan nilai logika kontinum (berlanjut) antara 0 dan 1 . Seperti pada Gambar 4 bukan hanya hitam dan putih, namun logika fuzzy menggunakan gradasi spektrum warna hitam menuju putih (Omar, 2010).

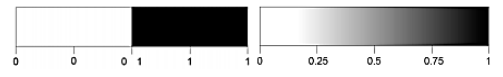

(a)

(b)

Gambar 4. (a) Rentang nilai logika Boolean (b) Logika fuzzy

\subsubsection{Aturan Dasar}

Aturan dasar (rule base) menjadi komponen utama dari sistem fuzzy yang mebawa beberapa tingkat kecerdasan dalam sistem. Ini berisi seperangkat aturan fuzzy yang terhubung anteseden (antecedents) dan konsekuensi (consequences), atau kondisi dengan aksinya (Omar, 2010). Dalam hal ini, pengetahuan dan pengalaman perancang harus diintepretasikan dengan benar dan diatur dalam seperangkat aturan yang sesuai aturan fuzzy yang dapat didefinisikan sebagai pernyataan kondisional dalam bentuk:

\section{IF $x$ is A THEN $y$ is B}

dimana $x$ dan $y$ adalah input dan output variabel yang mewakili nilai linguistik A dan B masing-masing. Nilai linguistik A dan B diwakili oleh himpunan fuzzy pada setiap semesta pembicaraannya. Dalam aturan fuzzy IF-THEN, bagian IF pada aturan ( $x$ adalah A) dikenal sebagai aturan anteseden (kondisi), sedangkan bagian THEN pada aturan ( $y$ adalah B) dikenal sebagai aturan konsekuensi (aksi).

\subsubsection{Fuzzifikasi}

Fuzzifikasi merupakan proses perubahan variabel numerik menjadi variabel linguistik. Fuzzifikasi berfungsi untuk mengubah nilai masukan krisp, misal $\mathrm{a} \in \mathrm{B}$, ke himpunan fuzzy $\mathrm{C}$ dengan nilai keanggotaan a (Omar, 2010). Fuzzifikasi diharapkan dapat membantu menyederhanakan komputasi yang harus dilakukan oleh sistem tersebut dalam proses inferensinya.

\subsubsection{Inferensi Fuzzy}

Inferensi fuzzy merupakan proses perumusan pemetaan dari input yang diberikan ke hasil output. Proses ini memiliki dua bagian yang berbeda, bagian pertama adalah mengevaluasi aturan anteseden dan bagian kedua adalah implikasi atau penerapan hasilnya ke dalam konsekuen (aksi).

\subsubsection{Defuzzifikasi}

Defuzzifikasi merupakan proses transformasi besaran fuzzy yang ditampilkan dalam bentuk himpunan-himpunan fuzzy keluaran dengan fungsi keanggotaannya untuk menghasilkan kembali bentuk bilangan krisp (Genther, Runkler and Glesner, 1994). Hal ini befungsi dalam implementasi nyata yang dibutuhkan adalah nilai krisp. Terdapat beberapa metode yang tersedia dalam defuzzifikasi, namun yang paling banyak digunakan adalah teknik weight average (WA), centroid. Teknik centroid memiliki konsep serupa dengan metode mencari nilai titik tengah suatu area (Liu, 2008).

\section{PERANCANGAN SISTEM GIMBAL}

Secara menyeluruh sistem gimbal terdiri dari sistem mekanika, sistem elektonika dan sistem kendali. Dari ketiga bagian sistem ini, semuanya memiliki peran yang penting dalam perancangan sistem gimbal, oleh karena itu desain sistem mekanika gimbal yang memperhatikan letak center of grafity (CoG) adalah suatu keharusan seperti yang disajikan pada Gambar 5. Untuk sistem elektronika pada sistem gimbal, kestabilan pembacaan sensor IMU adalah suatu peranan yang penting yang nantinya akan digunakan untuk data masukan dalam perancangan sistem kendalinya.

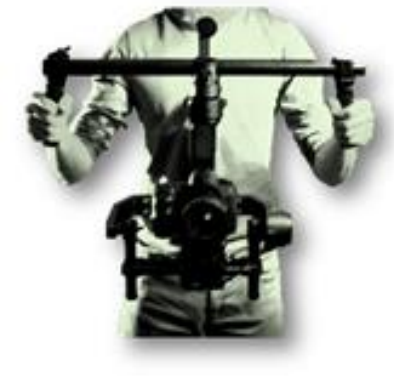

Gambar 5. Sistem gimbal kamera

\subsection{PERANCANGAN MEKANIKA}

Sistem gimbal memiliki konfigurasi mekanik dimana kamera sebagai titik tengah dari mekanik secara keseluruhan. Pada penelitian ini percancangan sistem gimbal menggunakan pipa paralon PVC berdiameter $25 \mathrm{~mm}$ dengan bentuk menyerupai huruf "M" dengan tujuan mempermudah dalam menghandling sistem gimbal seperti yang ditampilkan pada Gambar 6 dan Gambar 7. Selain itu dapat memperkokoh handling dalam memegang gimbal agar tidak mudah terjatuh ketika digunakan. Pengkabelan dimasukkan melalui bagian rongga dalam pipa PVC agar lebih rapih dan terisolasi dengan baik. Hasil rancangan 3D CAD mekanik handling pada penelitian ini disajikan pada Gambar 9. Dan rancangan 3D CAD mekanik sistem gimbal 
dengan tiga sumbu gerak serta hasil fisik rancangannya disajikan pada Gambar 8 dan Gambar 10.

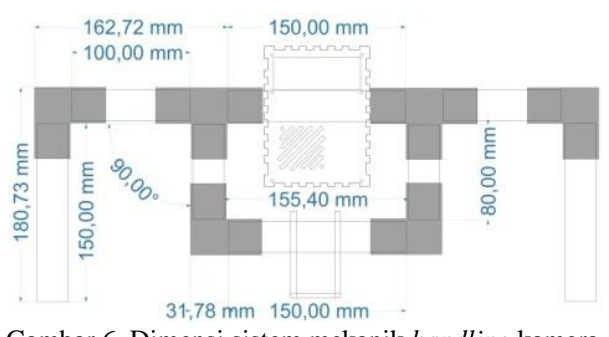

Gambar 6. Dimensi sistem mekanik handling kamera.

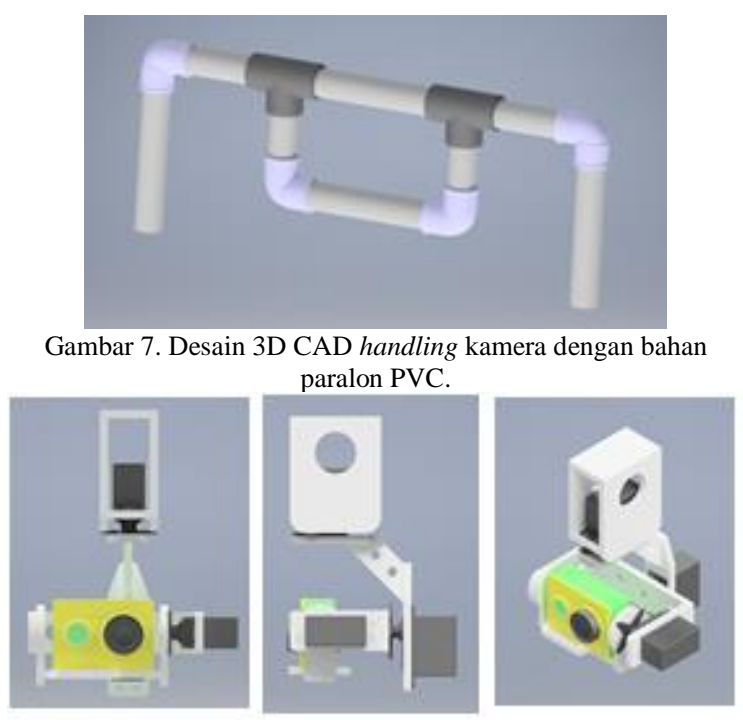

Gambar 8. Desain 3D CAD sistem gimbal dengan tiga buah sumbu gerak.

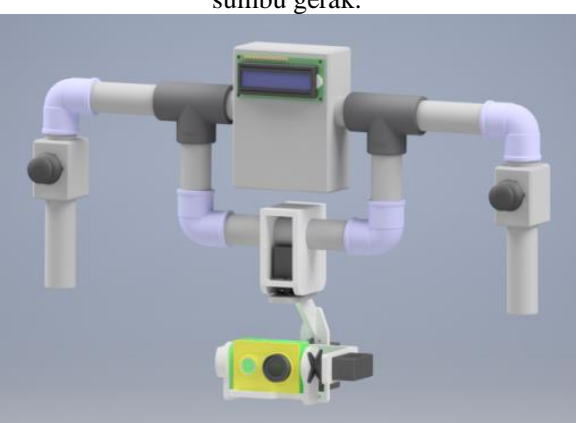

Gambar 9. Desain 3D CAD sistem gimbal secara keseluruhan.
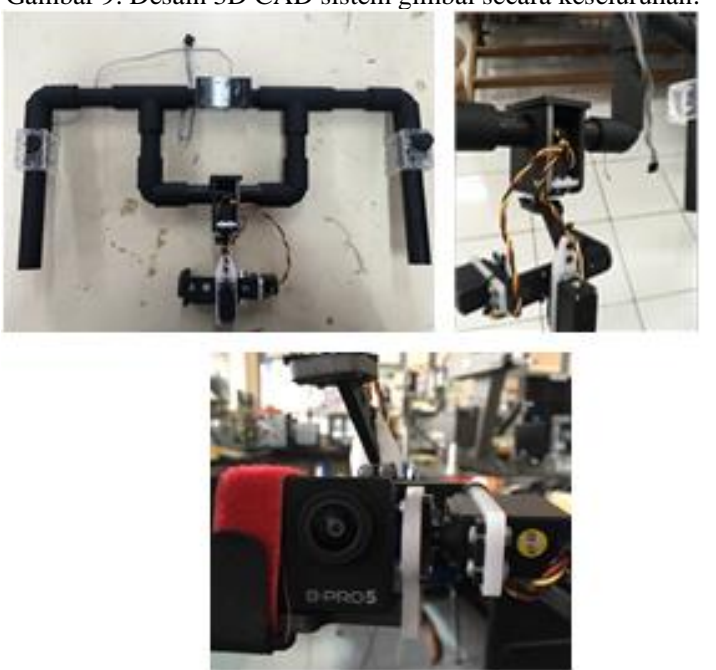

Gambar 10. Hasil fisik rancangan sistem gimbal.

\subsection{PERANCANGAN ELEKTRONIKA}

Sistem elektronika yang terdapat pada gimbal ialah terdiri dari perangkat dari sensor IMU MPU 6050, modul masukan setpoint dengan thumb analog button, perangkat Arduino Uno dan motorservo sebagai actuator pergerakan disetiap sumbu. Diagram blok dari sistem elektronika rancangan gimbal pada penelitian ini secara menyeluruh disajikan pada Gambar 11.

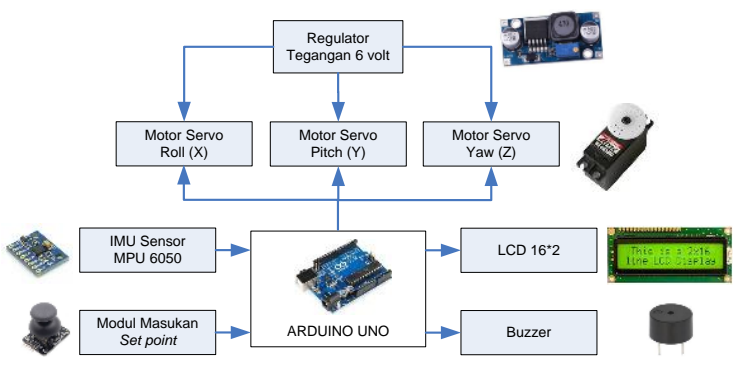

Gambar 11. Sistem elektronika gimbal.

\subsection{PERANCANGAN SISTEM KENDALI FUZZY}

Logika fuzzy yang diimplementasikan pada sistem gimbal ditanam kedalam Arduino Uno dengan istilah embeded fuzzy, artinya semua tahapan fuzzy diolah komputasinya dalam sebuah chip. Diagram blok sistem kendali fuzzy yang diimplementasikan pada sistem gimbal disajikan pada Gambar 12. Pada sistem gimbal ini variabel masukan untuk fuzzifikasi diperoleh dari hasil pembacaan sensor IMU yang berupa sudut kemiringan pada setiap sumbunya, yaitu $x, y, z$. Selisih dari setpoint (posisi stabil) dan pembacaan sensor IMU adalah nilai error dan perubahan nilai error setiap waktu disebut delta error. Lebih lanjut, error dan delta error ini yang kemudian menjadi masukan ke dalam fuzzifikasi dan merupakan fungsi keanggotaan masukan. Adapun penjelasan dari fungsi keanggotaan masukan dijabarkan sebagai berikut:

a) Fungsi keanggotaan error terdiri dari Large Negative (LN), Medium Negative (MN), Small Negative (SN), Zero (Z), Small Positive (SP), Medium Positive (MP), Large Positive (LP). Untuk nilai dari masing-masing fungsi keanggotaan error disajikan pada Gambar 13.

b) Fungsi keanggotaan derror terdiri dari Derror Large Negative (DLN), Derror Medium Negative (DMN), Derror Small Negative (DSN), Derror Zero (DZ), Derror Small Positive (DSP), Derror Medium Positive (DMP), Derror Large Positive (DLP). Untuk nilai dari masing-masing fungsi keanggotaan derror disajikan pada Gambar 14. 


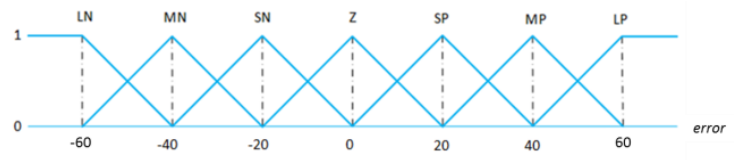

Gambar 13. Fuzifikasi keanggotaan error.

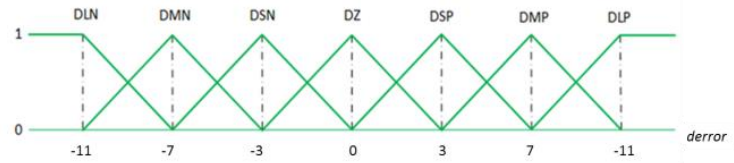

Gambar 14. Fuzifikasi keanggotaan derror.

Setelah didapatkan nilai linguistik berupa derajat keanggotaan dari setiap fungsi, selanjutnya nilai linguistik tersebut akan diolah pada tahapan proses inferensi. Dari fungsi keanggotaan fuzzifikasi yang terdiri dari tujuh derajat keanggotaan maka untuk aturan dasar terdiri dari 49 aturan dimana aturan tersebut antara lain dijelaskan pada Tabel 2 dengan mengacu pada aturan MacVicar Whelan. Berdasarkan daftar aturan tersebut maka dibentuk tabel komposisi aturan yang menjadi acuan implikasi dari masukan impunan fuzzy error dan derror. Aturan fuzzy yang digunakan pada implementasi quadrotor ini menggunakan inferensi dengan metode Mamdani (Mamdani, 1975) seperti yang dijelaskan pada persamaan (7).

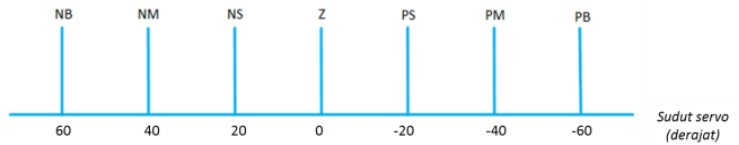

Gambar 15. Defuzifikasi dengan 7 singletones
Tabel 2. Tabel aturan fuzzy menggunakan konfigurasi dari MacVicar Whelan.

\begin{tabular}{|c|c|c|c|c|c|c|c|c|}
\hline & \multicolumn{7}{|c|}{ error } \\
\hline & & LN & MN & $\mathrm{SN}$ & Z & SP & MP & LP \\
\hline \multirow{7}{*}{ 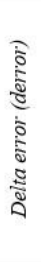 } & DLN & NB & NB & $\mathrm{NM}$ & $\mathrm{NM}$ & NS & NS & Z \\
\hline & $\mathrm{DMN}$ & NB & $\mathrm{NM}$ & $\mathrm{NM}$ & NS & NS & Z & PS \\
\hline & DSN & $\mathrm{NM}$ & $\mathrm{NM}$ & NS & NS & Z & PS & PM \\
\hline & $\mathrm{DZ}$ & $\mathrm{NM}$ & NS & NS & Z & PS & PM & PM \\
\hline & DSP & NS & NS & Z & PS & PM & PM & PB \\
\hline & DMP & NS & Z & PS & PM & PM & PB & PB \\
\hline & DLP & Z & PS & PM & PM & PB & PB & PB \\
\hline
\end{tabular}

$\mu_{y}(k)=\max \left[\min \left\{\mu_{u}(k), \mu_{r}(\operatorname{error}(i), \operatorname{derror}(j))\right\}\right]$

Nilai hasil pemetaan dari inferensi fuzzy tersebut akan diteruskan menuju tahap terakhir pada kendali logika fuzzy (Yoneyama, 2000). Pada tahap ini, nilai keluaran inferensi akan diubah kembali menjadi nilai krisp agar dapat diimplementasikan kembali pada sistem gimbal. Metode yang digunakan adalah weight average (WA) yang dijelaskan pada persamaan (8) . Untuk mengubah nilai linguistik tersebut diperlukan fungsi yang disesuaikan dengan rentang yang diperlukan oleh aktuator. Pada penelitian ini, tahapan defuzifikasi menggunakan singletone sebanyak tujuh buah. Nilai keluaran dari defuzzifikasi inilah yang digunakan sebagai nilai derajat sumbu putar pada ketiga servomotor. Pada setiap motor dapat dipengaruhi dari ketiga sudut roll, pitch, dan yaw. Himpunan keluaran krisp dari defuzzifikasi ini dijelaskan pada Gambar 15 .

$$
W A=\frac{\mu(k 1) \times k 1+\mu(k 2) \times k 2+\ldots \mu(k 7) \times k 7}{\mu(k 1)+\mu(k 2)+\ldots \mu(k 7)}
$$

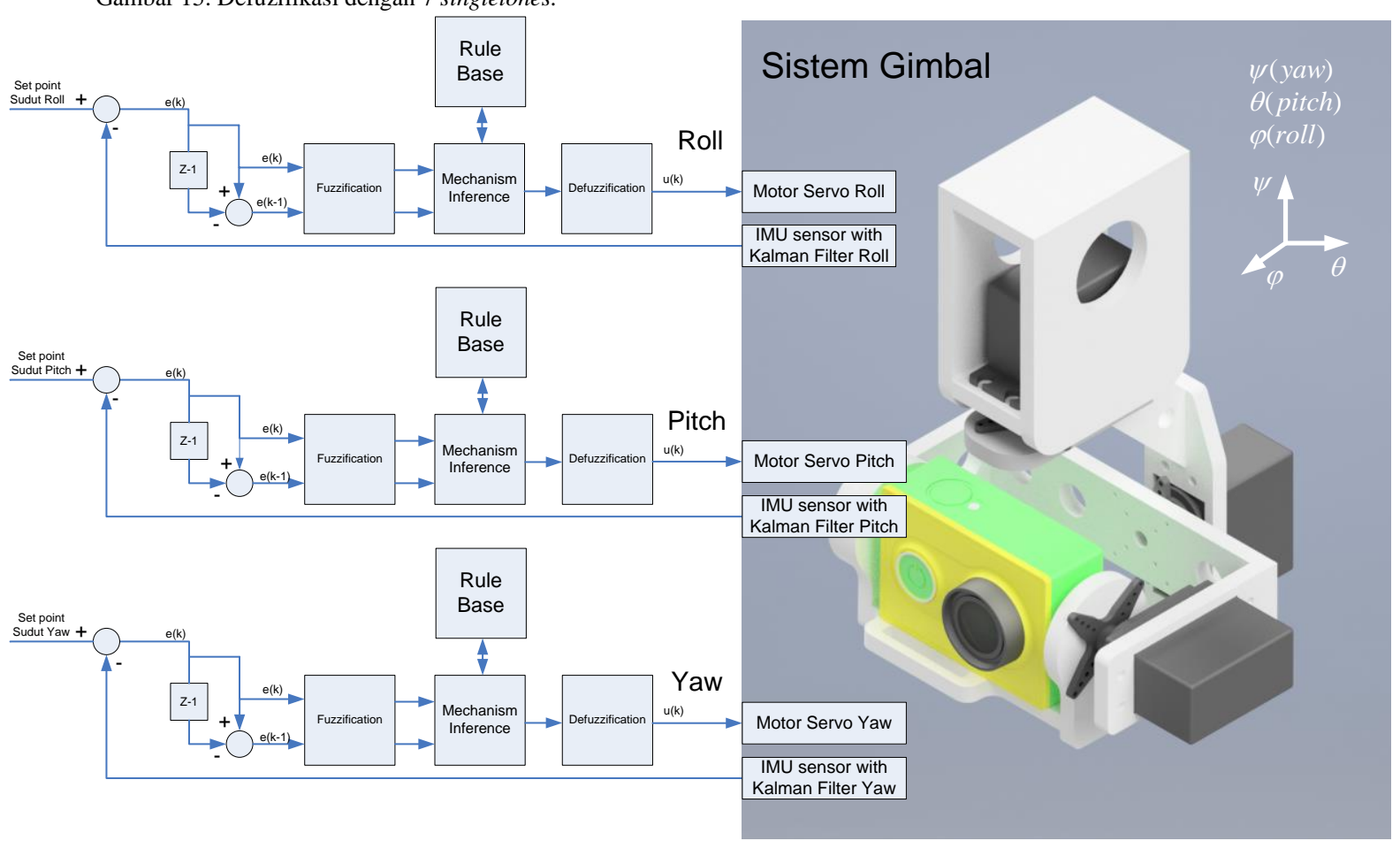

Gambar 12. Diagram blok kendali logika fuzzy pada sistem gimbal. 


\section{PENGUJIAN DAN PEMBAHASAN}

\subsection{PENGUJIAN FILTER KALMAN}

Hasil filter KF merupakan fundamental dalam mencapai kestabilan sistem gimbal. Setelah dilakukan pengujian dengan membandingkan dengan algoritma complementary filter $(\mathrm{CF})$ maka diperoleh suatu sinyal sensor IMU pada sumbu roll dan pitch seperti yang disajikan pada Gambar 16 dan Gambar 17. Pada Gambar merupakan grafik hasil pembacaan nilai sudut roll yang sudah diolah dengan $\mathrm{CF}$ dan $\mathrm{KF}$. Hasil yang ditampilkan pada setiap keluaran memiliki nilai yang hampir sama, namun pada saat perubahan yang besar terjadi perbedaan yang besar pula. Dari grafik perbandingan pembacaan ini dapat dilihat bahwa KF memiliki kelebihan dalam teknik penyaringan. Pada pengujian non-filter terdapat noise yang cukup besar pada saat terjadi perubahan sudut yang cepat. Hal ini dapat diketahui bahwa bila pembacaan sudut tanpa menggunakan filter akan mengalami perubahan nilai yang sangat cepat yang akan membuat noise pada hasil pembacaan.

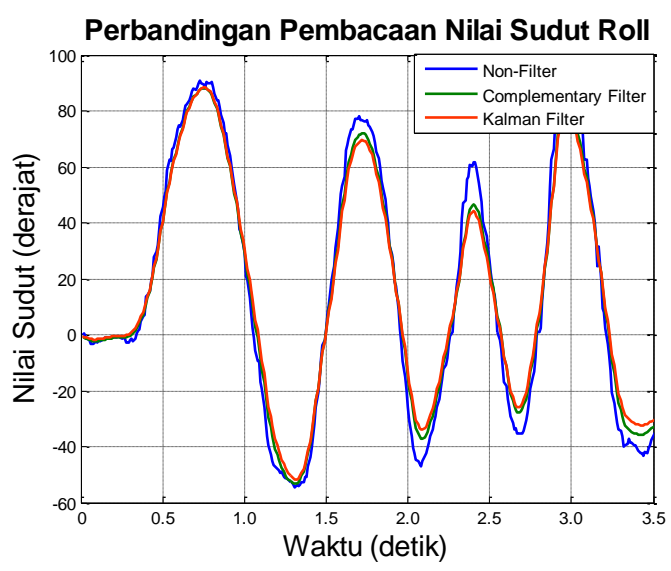

Gambar 16. Pembacaan sensor IMU pada sumbu roll.

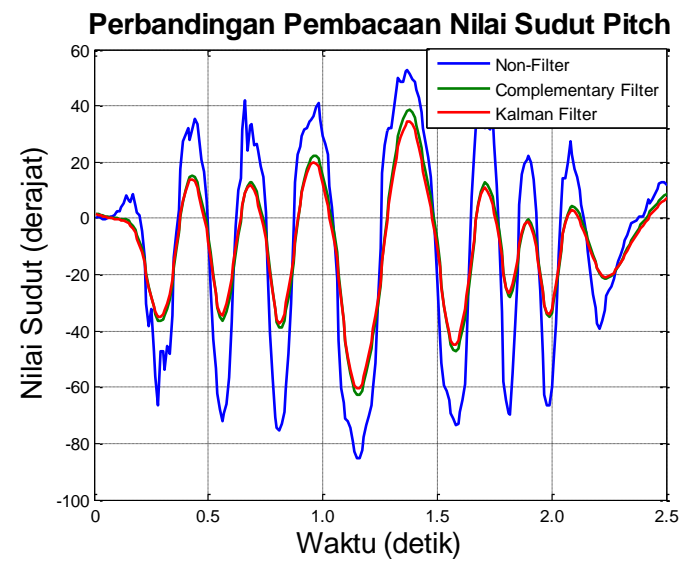

\subsection{PENGUJIAN LOGIKA FUZZY PADA SISTEM GIMBAL}

Pengujian dilakukan dengan menggunakan action camera B-Pro yang diletakan di titik kamera pada sistem gimbal. Kamera yang digunakan memiliki kualitas $4 \mathrm{~K}$ sehingga kualitas gambar dalam segi ketajaman tidak diperhitungkan disini melainkan kualitas sedikitnya blur dan melencengnya titik fokus kamera terhadap objek. Pada pengujian hasil pengambilan foto dan video, baik yang menggunakan sistem penstabil kendali logika fuzzy maupun yang tidak. Adapun item pergerakan sumbu yang diuji ialah sebagai berikut:

a) Pengujian pengambilan saat sistem gimbal digerakkan pada sumbu $x$ (pitch axis) seperti yang disajikan pada Tabel 3.

b) Pengujian pengambilan saat sistem gimbal digerakkan pada sumbu y (roll axis) seperti yang disajikan pada Tabel 4.

c) Pengujian pengambilan saat sistem gimbal digerakkan pada sumbu $z$ (yaw axis) seperti yang disajikan pada Tabel 5 .

d) Pengujian pengambilan saat sistem gimbal digerakkan pada sumbu $x, y$ dan $z$ (semua axis) seperti yang disajikan pada Tabel 6 .

Tabel 3. Pengujian pengambilan foto dan video saat sistem gimbal digerakkan pada sumbu pitch.

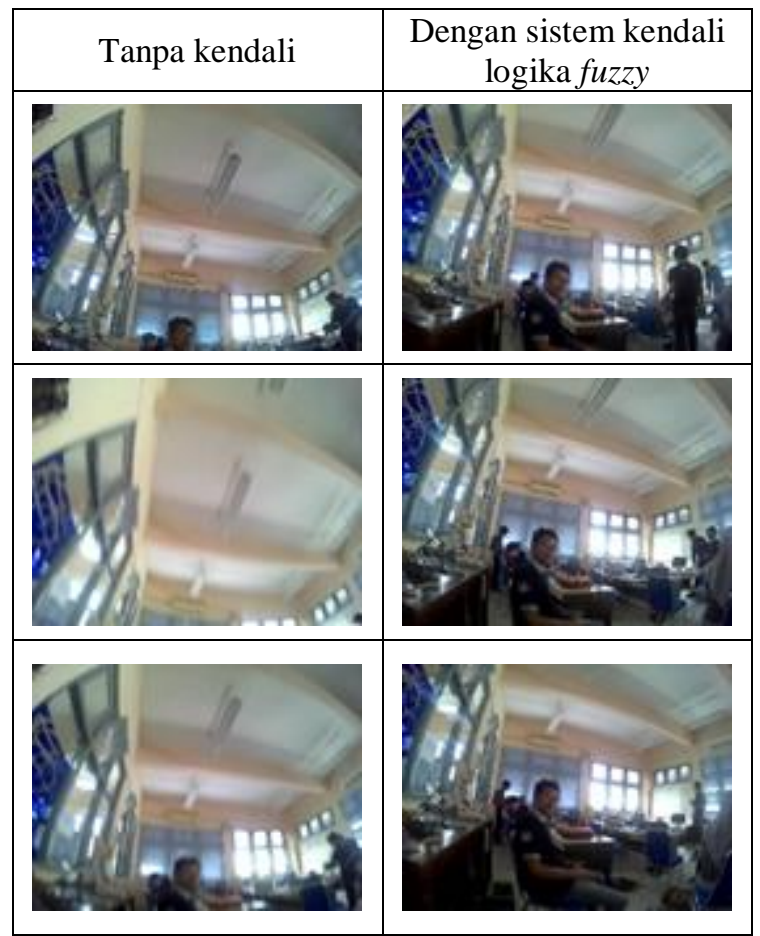


Tabel 4. Pengujian pengambilan foto dan video saat sistem digerakkan pada sumbu roll.

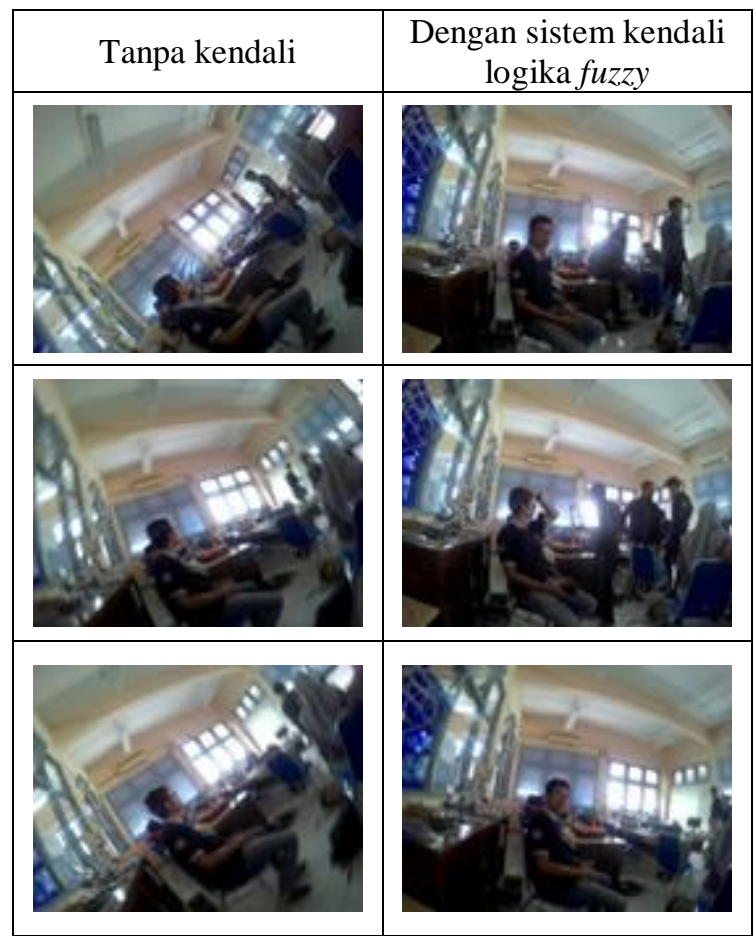

Tabel 5. Pengujian pengambilan foto dan video saat sistem digerakkan pada sumbu yaw.

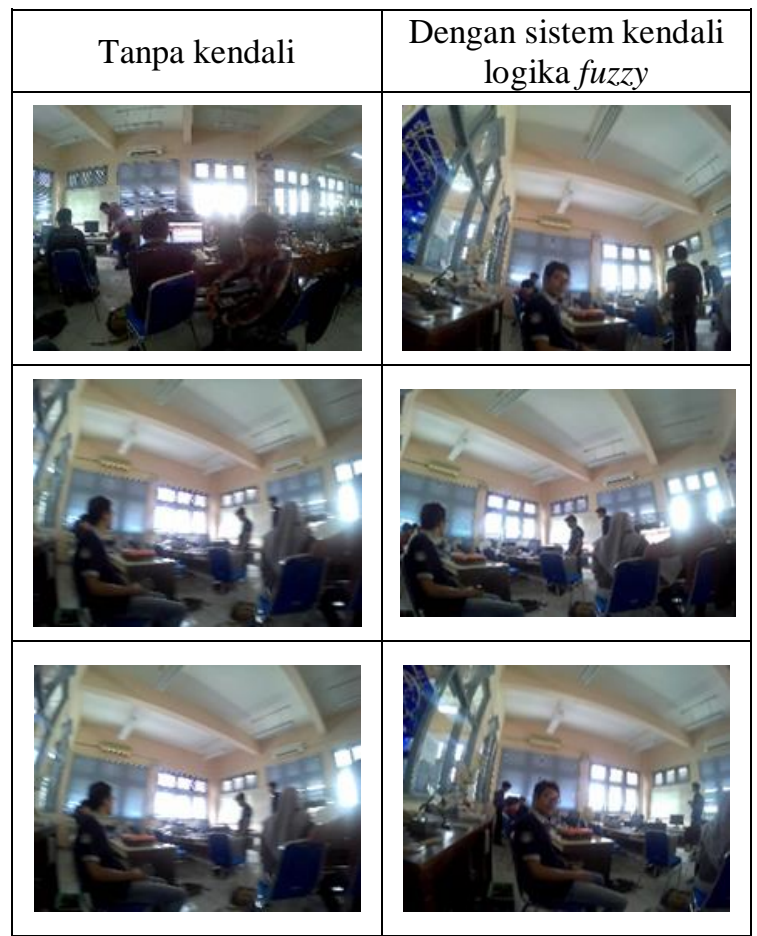

Dari hasil pengujian yang dilakukan, terlihat bahwa sistem gimbal yang telah diimplementasikan sistem kendali fuzzy mampu mempertahankan posisi kamera di tengah. Jika sistem gimbal digerakkan pada sumbu pitch, maka hasil pengambilan gambar juga akan bergerak naik dan turun mengikuti gerakan yang diberikan. Jika sistem digerakkan pada sumbu roll, maka hasil pengambilan gambar akan bergerak miring kekiri dan ke kanan. Begitu pula saat sistem digerakkan pada sumbu yaw, maka hasil pengambilan gambar akan bergerak menghadap ke kanan dan ke kiri.

Pada Gambar 18 menyajikan data error dan derror sudut gimbal pada sumbu pergerakan roll. Data yang disajikan merupakan hasil pergerakan gimbal pada pengujian pengambilan foto dan video saat sistem digerakkan pada sumbu roll seperti yang disajikan pada Tabel 4. Disini terlihat pergerakan error sudut gimbal bergerak pada range +25 derajat dan -25 derajat. Bila error sudut gimbal bernilai negatif maka gimbal berputar miring kekiri dan kekanan bila positif. Dan data perubahan derror bergerak pada range +10 derajat dan -10 derajat.

Selanjutnya, hasil dari proses fuzzifikasi error dan derror sudut gimbal diteruskan dan diproses pada sistem rule inference pada Tabel 2. Setelah itu dilakukan proses defuzzfikasi menggunakan metode WA seperti yang disajikan pada persamaan (8). Hasil dari defuzzifikasi ini merupakan sudut servo rool pada gimbal seperti yang disajikan pada Gambar 19 .

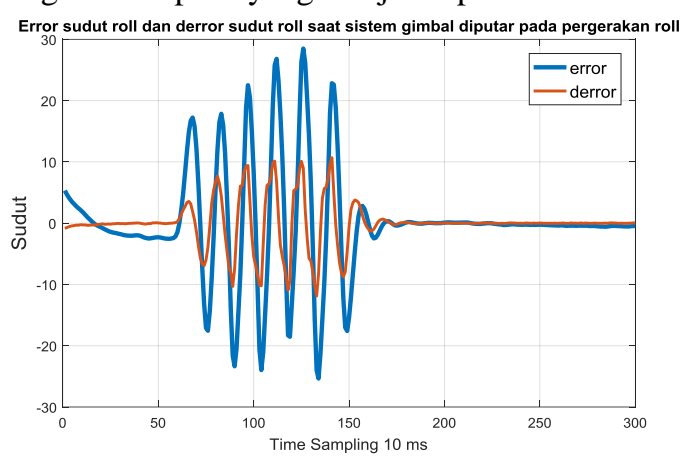

Gambar 18. Error sudut roll dan derror sudut roll saat sistem diputar pada pergerakan roll dengan waktu cuplik setiap $10 \mathrm{~ms}$ selama 3 detik.

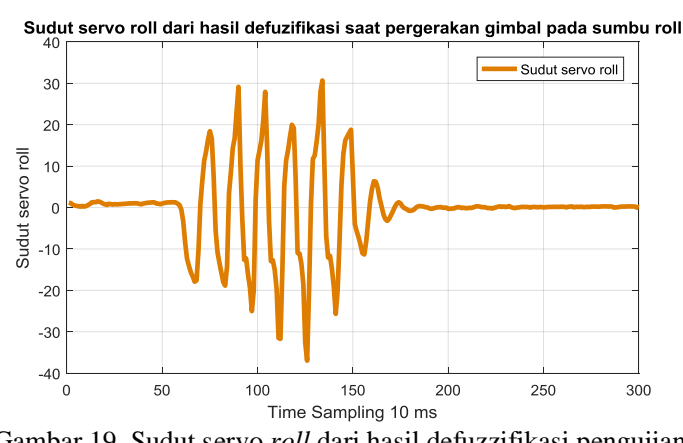

Gambar 19. Sudut servo roll dari hasil defuzzifikasi pengujian Tabel 4 saat sistem gimbal diuji pada pergerakan sumbu roll.

Bila diperhatikan hubungan antara sudut servo roll dengan error sudut gimbal saat digerakan pada sumbu putar roll maka dapat ditarik simpulan bahwa pergerakan servo gimbal akan melawan arah dari error sudut roll seperti yang disajikan pada Gambar 20. Hasil ini mengakibatkan posisi kamera akan 
berada ditengah. Sehingga pegambilan gambar foto dan video akan berada pada posisi tengah.

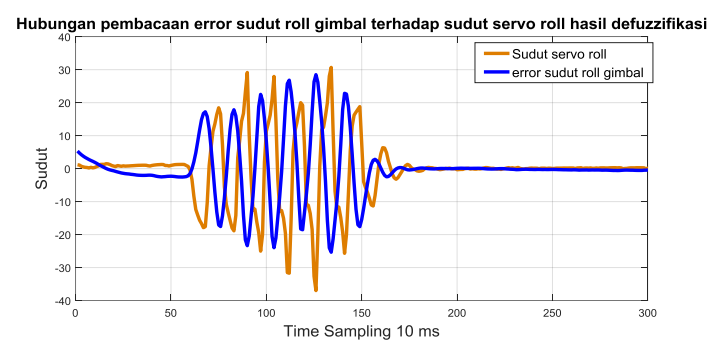

Gambar 20. Hubungan antara sudut servo roll dengan error sudut gimbal saat digerakan pada sumbu putar roll.

Dari hasil percobaan implementasi kendali logika fuzzy pada sistem gimbal diperoleh hasil bahwa sistem ini mampu menahan posisi kamera pada posisi tengah gimbal, sehingga apabila terjadi goncangan saat pengambilan gambar dapat diminimalisir. Namun hasil yang diperoleh pada penelitian ini masih mengalami sedikit goncangan. Hal ini berhubungan dengan perilaku motor servo yang bergerak sedikit terlambat menuju setpoint. Hal ini dapat dilakukan dengan menggantikan motor servo dengan sebuah motor brushless.

Tabel 6. Pengujian pengambilan saat sistem gimbal digerakkan pada sumbu $x, y$ dan $z$ (semua sumbu).

\begin{tabular}{|c|c|}
\hline Tanpa kendali & $\begin{array}{c}\text { Dengan sistem kendali } \\
\text { logika fuzzy }\end{array}$ \\
\hline & \\
\hline
\end{tabular}

\section{KESIMPULAN}

Dari serangkaian pengujian, dan analisis yang telah dilakukan pada sistem gimbal dapat disimpulkan bahwa sistem gimbal telah berhasil dibuat menggunakan sistem kendali logika fuzzy. Respon motor servo masih sedikit terlambat dalam melakukan koreksi posisi. Selanjutnya, sistem gimbal dengan dilengkapi kendali logika fuzzy mampu meningkatkan kualitas pengambilan gambar foto dan video bila dibanding dengan tidak menggunakannya. Semakin extreme ganguan yang diterima gimbal maka akan mempemengaruhi kesempurnaan hasil pengambilan gambar foto dan video.

\section{DAFTAR PUSTAKA}

LIU, F. 2008. An efficient centroid type-reduction strategy for general type-2 fuzzy logic system.
Information Sciences, 178(9), pp.2224-2236.

CROCE, A., POSSAMAI, R., SAVORANI, A., \& TRAINELLI, L. 2014. Modelling and characterization of a novel gimbal two-blade helicopter rotor. In 40th European Rotorcraft Forum 2014.

FAHMIZAL, SETYAWAN, G., ARROFIQ, M. \& MAYUB, A., 2017. Logika Fuzzy pada Robot Inverted Pendulum Beroda Dua. Jurnal Teknologi Informasi dan Ilmu Komputer, 4(4), pp.244-252.

GENTHER, H., RUNKLER, T. A. \& GLESNER, M. 1994. Defuzzification Based on Fuzzy Clustering. In Proceedings of the Third IEEE Conference on Fuzzy Systems, 1994. IEEE World Congress on Computational Intelligence.

HARIS, M.S., DHARMAWAN, A. \& ATMAJI, C., Sistem Kendali Gimbal 2-Sumbu Sebagai Tempat Kamera Pada Quadrotor Menggunakan PID Fuzzy. IJEIS (Indonesian Journal of Electronics and Instrumentation Systems), 7(2), pp.185-196.

KALMAN, R.E.1963. New methods in Wiener filtering theory. In Proceedings of the First Symposium on Engineering Applications of Random Function Theory and Probability, edited by JL Bogdanoff and F. Kozin, John Wiley \& Sons, New York.

KNOBLAUCH, H., TUMA, R. \& SCHNETTLER, B. 2014. Videography. Peter Lang.

MAMDANI, EBRAHIM H., \& SEDRAK ASSILIAN. An experiment in linguistic synthesis with a fuzzy logic controller." International journal of man-machine studies 7, no. 1 (1975): 1-13.

OMAR, Z. M. E. 2010. Intelligent Control of a Ducted-Fan VTOL UAV with Conventional Control Surfaces, System. RMIT University.

PRIYAMBODO, T.K. 2017. Implementasi Sistem Kendali PID pada Gimbal Kamera 2-sumbu dengan Aktuator Motor Brushless. IJEIS (Indonesian Journal of Electronics and Instrumentation System), 7(2), pp.117-126.

SHAH, S.V., SAHA, S.K. AND DUTT, J.K. 2012. Denavit-Hartenberg Parameterization of Euler Angles. Journal of Computational and Nonlinear Dynamics, 7(2), p.021006.

UBAYA, H. AND MAWARNI, H. 2015. Sensor Fusion and Fuzzy Logic for Stabilization System of Gimbal Camera on Hexacopter. ICON-CSE, 1(1), pp.25-32.

YONEYAMA, JUN, MASAHIRO NISHIKAWA, HITOSHI KATAYAMA, \& AKIRA ICHIKAWA. Output stabilization of TakagiSugeno fuzzy systems. Fuzzy sets and Systems 111, no. 2 (2000): 253-266. 
Halaman ini sengaja dikosongkan 
Fahmizal, dkk, Rancang Bangun Sistem Penstabil Kamera ... 287 